\title{
Chondrogenesis of periodontal ligament stem cells by transforming growth factor- $\beta 3$ and bone morphogenetic protein-6 in a normal healthy impacted third molar
}

\author{
Sunyoung Choi ${ }^{1,2, *}$, Tae-Jun Cho ${ }^{1,2, *}$, Soon-Keun Kwon ${ }^{1,2}$, Gene Lee $^{2,3}$ and Jaejin Cho ${ }^{1,2}$
}

The periodontal ligament-derived mesenchymal stem cell is regarded as a source of adult stem cells due to its multipotency. However, the proof of chondrogenic potential of the cells is scarce. Therefore, we investigated the chondrogenic differentiation capacity of periodontal ligament derived mesenchymal stem cells induced by transforming growth factor (TGF)- $\beta 3$ and bone morphogenetic protein (BMP)-6. After isolation of periodontal ligament stem cells (PDLSCs) from human periodontal ligament, the cells were cultured in Dulbecco's modified Eagle's medium (DMEM) with $20 \%$ fetal bovine serum (FBS). A mechanical force initiated chondrogenic differentiation of the cells. For chondrogenic differentiation, $10 \mu \mathrm{g} \cdot \mathrm{L}^{-1} \mathrm{TGF}-\beta 3$ or $100 \mu \mathrm{g} \cdot \mathrm{L}^{-1} \mathrm{BMP}-6$ and the combination treating group for synergistic effect of the growth factors. We analyzed the PDLSCs by fluorescence-activated cell sorting and chondrogenesis were evaluated by glycosaminoglycans assay, histology, immunohistochemistry and genetic analysis. PDLSCs showed mesenchymal stem cell properties proved by FACS analysis. Glycosaminoglycans contents were increased $217 \%$ by TGF- $\beta 3$ and $220 \%$ by BMP-6. The synergetic effect of TGF- $\beta 3$ and BMP- 6 were shown up to $281 \%$ compared to control. The combination treatment increased Sox9, aggrecan and collagen II expression compared with not only controls, but also TGF- $\beta 3$ or BMP- 6 single treatment dramatically. The histological analysis also indicated the chondrogenic differentiation of PDLSCs in our conditions. The results of the present study demonstrate the potential of the dental stem cell as a valuable cell source for chondrogenesis, which may be applicable for regeneration of cartilage and bone fracture in the field of cell therapy.

International Journal of Oral Science (2013) 5, 7-13; doi:10.1038/ijos.2013.19; published online 12 April 2013

Keywords: bone morphogenetic protein-6; chondrogenesis growth factor; periodental ligament cell; stem cell; transforming growth factor- $\beta 3$

\section{INTRODUCTION}

Stem cells are undifferentiated, have the potential to proliferate without differentiation, and can change their identity in an organ specific manner. ${ }^{1}$ Adult tissues include not only fully differentiated and specialized cells, but also pluripotent cells, which function similarly to embryonic stem cells, and are called adult stem cells. These adult stem cells have been focused upon as a promising tool for understanding tissue development and regeneration. ${ }^{2}$ Stem cells are also present in dental tissues, including dental pulp, periapical follicles and periodontal ligaments. ${ }^{3}$

Periodontal ligaments (PDLs) are a specialized connective tissue, consisting mainly of collagen fibers that attach a tooth to the alveolar bone. The fibers help the tooth withstand the loading during chewing and remain embedded in the alveolar bone socket. PDLs also contain several cellular components such as fibroblasts, osteoblasts and cementoblasts. ${ }^{4}$ PDL-derived mesenchymal stem cells have the ability to regenerate periodontal tissues and pulp. A previous study reported that during the periodontal wound healing process, these cells migrated from the residual PDL to regenerate alveolar bone tissue. ${ }^{4}$ Recently, several studies reported the pluripotency of periodontal ligament cells. ${ }^{4-8}$ It was found that cells in the periodontal ligament express markers of bone marrow mesenchymal stem cells, which suggests that stem cells are present in the periodontal ligament. ${ }^{5-6}$ Under specialized conditions, these stem cells, called periodontal ligament stem cells (PDLSCs), differentiated into cementoblast-like cells and adipocyte-like cells, and even exhibited the capacity to generate a structure similar to cementum and PDL architecture when transplanted into immunocompromised rodents. ${ }^{5,8}$ Additionally, it was reported that these cells might have the potential to differentiate into chondrocyte-like cell types and express small amounts of collagen type II and glycosaminoglycans (GAG) in chondrogenesis-inducing cultures. $^{7}$ Chondrogenesis of PDLSCs has also been attempted with demineralized dentin implanted into PDLs in vivo; ${ }^{9}$ however, the purpose of these trials was simply to demonstrate the multipotent ability of PDLSCs.

${ }^{1}$ Laboratory of Developmental Biology and Stem Cell Differentiation/Transplantation, Department of Dental Regenerative Biotechnology, School of Dentistry, Seoul National University, Seoul, Korea; ${ }^{2}$ Dental Research Institute, School of Dentistry, Seoul National University, Seoul, Korea and ${ }^{3}$ Laboratory of Molecular Genetics, School of Dentistry, Seoul National University, Seoul, Korea

*These authors contributed equally to this work.

Correspondence: Dr J Cho, Laboratory of Developmental Biology and Stem Cell Differentiation/Transplantation, Department of Dental Regenerative Biotechnology, School of Dentistry, Seoul National University, 28 Yongun-dong, Chongno-gu, Seoul 110-739, Korea

E-mail: jcho@snu.ac.kr

Received 14 May 2012; accepted 14 January 2013 
Chondrogenesis is defined as the process through which mesenchymal stem cells differentiate into chondroblasts that subsequently develop into either adult chondrocytes or undergo hypertrophy and apoptosis. ${ }^{10}$ Chondrogenesis of stem cells has been focused upon to complement the low self-repairing ability of natural articular cartilage. Unlike most natural tissues, articular cartilage has only a limited capacity for self-repair, and thus even minor damage can have detrimental effects. Specifically, it is the damage of the related articular cartilage that causes osteoarthritis, which is a very irritable and painful disease and substantially decreases quality of life. Until now, treatment of this disease focused on assuaging symptoms. Although numerous biological approaches for articular cartilage repair have been attempted, they are still experimental and their efficacy is questionable. However, replacement of damaged cartilage with new cartilage may be a solution to this condition. Indeed, cell therapy using chondrocytes or their precursors embedded in some biocompatible scaffold is a possible approach for cartilage reconstruction. ${ }^{2}$ Finding proper cells that can differentiate into chondrocytes, as well as identifying the conditions necessary for inducing chondrogenesis is a first step for the regeneration of articular cartilage. Furthermore, formation of artificial cartilage could be applied to plastic surgery of the nose or ears.

Thus, the aim of this study was to demonstrate the stem cell properties of PDLSCs by inducing chondrogenesis with the known chondrogenic growth factors transforming growth factor (TGF)- $\beta$ and bone morphogenetic protein (BMP)-6 in order to contribute to a better understanding of the development of articular cartilage. Furthermore, the results suggest a potential step toward the formation of artificial cartilage.

\section{MATERIALS AND METHODS}

\section{Cell isolation and cell culture}

PDL-derived cells were obtained from the normal healthy impacted third molar of a patient at Seoul National University Dental Hospital; this protocol was approved by the Institutional Review Boards (IRB) of Seoul National University Medical Ethics Committee. After washing the tooth with fresh Hank's balanced salt solution (HBSS) supplemented with a 3\% antibiotic-antimycotic solution (GIBCO, Grand Island, NY, USA), PDL tissue was separated from the surface of the tooth and digested in $1 \mathrm{~g} \cdot \mathrm{L}^{-1}$ collagenase type $\mathrm{I}$ and $2.4 \mathrm{~g} \cdot \mathrm{L}^{-1}$ dispase (GIBCO, Grand Island, NY, USA) for $1 \mathrm{~h}$ at $37^{\circ} \mathrm{C}$, followed by filtering through $100 \mu \mathrm{m}$ mesh. The solution was then centrifuged at $400 \mathrm{~g}$ for 4 min at $4{ }^{\circ} \mathrm{C}$ and the resulting cell PDL-derived cell pellet was resuspended in Dulbecco's modified Eagle's medium (DMEM; Welgene, Daegu, Korea) containing 20\% fetal bovine serum (FBS; HyClone Laboratories, Vancouver, Canada). The cells were cultured in DMEM solution containing 20\% FBS (HyClone Laboratories, Vancouver, Canada) with a $1 \%$ antibiotic-antimycotic solution at $37{ }^{\circ} \mathrm{C}$ in a $5 \%$ $\mathrm{CO}_{2}$ humidified atmosphere. Cells at the sixth passage were used for experiments. $^{11}$

\section{Chondrogenic differentiation}

To trigger chondrogenesis of PDLs, a mechanical force formed threedimensional (3D) cell cluster was created using 250000 PDLs per cluster by centrifugation at $500 \mathrm{~g}$ for $5 \mathrm{~min}$ at $4{ }^{\circ} \mathrm{C} .{ }^{12}$ The PDL-derived $3 \mathrm{D}$ clusters were differentiated with TGF- $\beta 3$ and BMP-6, which are known chondrogenic growth factors for mesenchymal stem cells derived from bone marrow and adipose tissue. Defined medium, which was optimized in our lab, consisted of $100 \mathrm{nmol} \cdot \mathrm{L}^{-1}$ dexametasone, $50 \mathrm{mg} \cdot \mathrm{L}^{-1}$ ascorbate-2-phosphate, $100 \mathrm{mg} \cdot \mathrm{L}^{-1}$ sodium pyruvate, $40 \mathrm{mg} \cdot \mathrm{L}^{-1} \mathrm{~L}$-proline and $1 \%$ ITS + Premix (all Sigma-Aldrich, St.
Louis, MO, USA) based on high-glucose DMEM; this media served as a control. For chondrogenesis, the defined media was supplemented with either $10 \mu \mathrm{g} \cdot \mathrm{L}^{-1} \mathrm{TGF}-\beta 3$ (R\&D Systems, Minneapolis, MN, USA) or $100 \mu \mathrm{g} \cdot \mathrm{L}^{-1}$ BMP-6 (R\&D Systems, Minneapolis, MN, USA). To evaluate the synergistic effects of both TGF- $\beta 3$ and BMP- 6 for chondrogenesis on human PDLSCs (hPDLSCs), a defined media containing both TGF- $\beta 3$ and BMP was used. We maintained the chondrogenic differentiation process for 14 days.

\section{Fluorescence-activated cell sorting analysis}

For fluorescence-activated cell sorting (FACS) analysis, hPDLSCs were harvested on day 14 of culture after isolation and purification. The cells were washed with phosphate buffer solution (PBS) and then stained with the following antibodies: fluorescein isothiocyanate (FITC)conjugated mouse anti-human CD14, CD31, CD44 and CD45; phycoerythrin (PE)-conjugated mouse anti-human CD29, CD73 and CD117; PE.Cy5-conjugated mouse anti-human CD90; antigen-presenting cellconjugated mouse anti-human CD34 and HLA-DR; streptavidinconjugated PE; biotin-conjugated HLA class I (all from BD, San Diego, CA, USA); and antigen-presenting cell-conjugated mouse anti-human CD105 (eBioscience, San Diego, CA, USA). Each primary antibody was incubated with 100000 cells for $30 \mathrm{~min}$ on ice. After washing, the secondary antibody was applied for $30 \mathrm{~min}$ on ice and then cells were fixed with $4 \%$ paraformaldehyde at $4{ }^{\circ} \mathrm{C}$. The fluorescence intensity was measured with a FACSCalibur flow cytometer (BD, San Diego, CA, USA) and data were analyzed via FLOWJO software (Tree Star, Inc., San Carlos, CA, USA).

\section{Macroscopic analysis}

hPLDSC pellets were observed on day 14 using a stereoscopic microscope (SMZ645; Nikon, Tokyo, Japan) and photographs were taken with a microruler for size analysis.

\section{GAGs assay}

The level of sulfated GAGs in the hPDLSC pellets harvested on day 14 of culture was measured using a Blyscan Sulfate Glycosaminoglycan Assay (Biocolor Ltd, Belfast, Ireland) according to the manufacturer's instructions. Pellets were digested in $1 \mathrm{~mL}$ Papain buffer $(100 \mathrm{~mL}$ of $0.2 \mathrm{~mol} \cdot \mathrm{L}^{-1}$ sodium phosphate buffer, $0.1 \mathrm{~mol} \cdot \mathrm{L}^{-1}$ sodium acetate, $10 \mathrm{nmol} \cdot \mathrm{L}^{-1}$ ethylene diaminetetraacetin acid (EDTA), $5 \mathrm{mmol} \cdot \mathrm{L}^{-1}$ L-cysteine and $\mathrm{HCl}, \mathrm{pH} 6.4$ ) with $10 \mathrm{mg} \cdot \mathrm{L}^{-1}$ of papain for $24 \mathrm{~h}$ in a $60{ }^{\circ} \mathrm{C}$ water bath, and then centrifuged at $3300 \mathrm{~g}$ for $5 \mathrm{~min}$. Absorbance of the samples was measured with an enzyme-linked immunosorbent assay (ELISA) reader (S500; BIO-RAD, Hercules, CA, USA) at $656 \mathrm{~nm}$ and chondroitin-4-sulfate solution was used as a standard. Total cellular DNA content was measured using a pico-green dsDNA assay kit (Invitrogen, Camarillo, CA, USA) according to the manufacturer's instructions. The level of GAGs was normalized versus the total amount of DNA.

\section{Total RNA extraction and reverse transcription-polymerase chain} reaction

On day 14, total RNA was extracted from hPDLSC pellets using Trizol reagent (Invitrogen, Carlsbad, CA, USA) and treated with DNase I (Roche, Mannheim, Germany) to remove possible DNA contaminants. The RNA was reverse-transcribed into complementary DNA by M-MLV reverse transcriptase (Invitrogen, Camarillo, CA, USA) according to the manufacturer's protocols. The amount of cDNA was determined by PCR using AccuPower PCR PreMix (Bioneer, Daejeon, Korea) according to the manufacturer's instructions. In this 
Table 1 Primers for PCR

\begin{tabular}{|c|c|c|c|c|}
\hline Target genes & Sequences & Annealing temperature $/{ }^{\circ} \mathrm{C}$ & Size/bp & Cycles \\
\hline COLI & $\begin{array}{l}\text { F: 5'-GGACACAATGGATTGCAAGG-3' } \\
\text { R: 5'-TAACCACTGCTCCACTCTGG-3' }\end{array}$ & 54 & 461 & 28 \\
\hline COLII & $\begin{array}{l}\text { F: 5'-TGGCCTGAGACAGCATGAC-3' } \\
\text { R: 5'-AGTGTTGGGAGCCAGATTGT-3' }\end{array}$ & 58 & 373 & 35 \\
\hline $\operatorname{coL} X$ & $\begin{array}{l}\text { F: 5'-GAACATCACCTACCACTGCAAG-3' } \\
\text { R: 5'-GCAGAGTCCTAGAGTGACTGAG-3' }\end{array}$ & 58 & 468 & 35 \\
\hline soxg & $\begin{array}{l}\text { F: 5'-ATCTGAAGAAGGAGAGCGAG-3' } \\
\text { R: 5'-TCAGAAGTCTCCAGAGCTTG-3' }\end{array}$ & 60 & 264 & 35 \\
\hline RUNX2 & $\begin{array}{l}\text { F: 5'-CAGAACCCACGGCCCTCCCT-3' } \\
\text { R: 5'-TCTGAAGCACCTGAAATGCGCCT-3' }\end{array}$ & 64 & 242 & 35 \\
\hline GAPDH & $\begin{array}{l}\text { F: 5'-TGTTGCCATCAATGACCCCTT-3' } \\
\text { R: 5'-CTCCACGACGTACTCAGCG-3' }\end{array}$ & 55 & 202 & 35 \\
\hline
\end{tabular}

way, the gene expression level of chondrogenic markers including collagen type I, II and X; SOX9, RUNX2; and aggrecan in the pellets was measured and normalized to their glyceraldehyde-3-phosphate dehydrogenase mRNA level (Table 1).

\section{Histological and immunohistochemical analysis}

Three-dimensional hPDLSC pellets harvested after 14 days of culture were embedded in paraffin and sectioned as 4 - $\mu \mathrm{m}$-thick slices. The paraffin sections were deparaffinized using Histo-clear II (Natural Diagnostics, Blackburg, VA, USA) and hydrated in alcohol. The specimens were stained with hematoxylin and eosin (Sigma-Aldrich, St. Louis, MO, USA) to identify and evaluate cell morphology. GAGs were visualized by staining with alcian blue (Wako, Osaka, Japan) and safranin-O/fast green (Fisher, Fair Lawn, NJ, USA).

Synthesized type I collagen in the pellets was detected by immunohistochemical staining using the ABC kit (Invitrogen, Camarillo, CA, USA) according to the manufacturer's instructions. Briefly, deparaffinized sections were hydrated with gradual concentrations of ethanol and incubated with serum blocking solution (Invitrogen, Camarillo, CA, USA) for 30 min to block non-specific background on the slides. The specimens were then stained with polyclonal rabbit anti-human type I collagen (Abcam, Cambridge, UK) as a primary antibody and incubated for $60 \mathrm{~min}$ at room temperature. After washing with Dulbecco's phosphate-buffered saline (DPBS; GIBCO, Grand Island, NY, USA), they were incubated again with anti-rabbit IgG (Invitrogen, Camarillo, CA, USA), a secondary antibody, for $30 \mathrm{~min}$. Type I collagen was visualized by applying streptavidin-HRP-conjugated tertiary antibody (Invitrogen, Camarillo, CA USA), followed by diaminobenzidine (DAB kit; Invitrogen, Camarillo, CA, USA). The same procedures were followed for staining of type II collagen, except monoclonal mouse anti-human type II collagen (Calbiochem, Darmstadt, Germany) as a primary antibody and anti-mouse IgG (Invitrogen, Camarillo, CA, USA) as a secondary antibody were used.

\section{Statistical analysis}

Four independent experiments were performed in triplicate and the data are presented as means \pm s.d. Data analysis was performed using Student's $t$-test at a significance level of $P<0.05$.

\section{RESULTS}

\section{FACS analysis and macroscopic analysis}

For the characterization of hPDLSC properties, we analyzed stem cell surface markers by FACS. Mesenchymal stem cell markers were homogeneously expressed in the cells as follows: $99.73 \%$ CD29, 99.54\%
CD44, 97.55\% CD73, 84.80\% CD90 and 51.54\% CD105. The hematopoietic and endothelial markers were expressed in a small number of cells as follows: $0.3 \%$ CD 14, 0.17\% CD31, 0.35\% CD34, 0.16\% CD45, $0.17 \%$ CD117 and $0.65 \%$ HLA-DR. These results are consistent with previously published data (Figure 1a). ${ }^{6,13-15}$ The size of the chondroclusters was measured with a stereoscopic microscope and a microruler. Although the chondroclusters were each treated in a different medium, they were similar in size, approximately $0.7 \mathrm{~mm}$ (Figure 1b).

\section{GAG assay}

The sulfated GAG contents of the pellets were measured after 14 days and normalized according to the total amount of cellular DNA. GAG synthesis was increased by $217 \%$ in cells treated with $10 \mu \mathrm{g} \cdot \mathrm{L}^{-1} \mathrm{TGF}-$ $\beta 3$ and by $220 \%$ in those treated with $100 \mu \mathrm{g} \cdot \mathrm{L}^{-1}$ BMP- 6 . The combination treatment of TGF- $\beta 3$ and BMP- 6 induced an even higher increase in GAG content (281\%). Further, the medium containing both growth factors induced GAG synthesis $130 \%$ more than TGF$\beta 3$ alone and 128\% more than BMP-6. The increases in GAG levels were all statistically significant $(P<0.01)$. Total DNA levels, which reflected the viability and proliferation of cells in the four conditions, were similar, indicating that these results are reliable (Figure 2).

\section{Reverse transcription-polymerase chain reaction}

The expression of genetic markers related to chondrogenesis was measured by reverse transcription-polymerase chain reaction (RT-PCR). The genes assayed in this experiment were SOX9, aggrecan, collagen type II, collagen type I, collagen type X and RUNX2. hPDLSCs cultured in the defined media expressed all markers except collagen type X. Both TGF- $\beta 3$ and BMP-6 increased the expression of SOX9, which is known as a critical chondrogenesis related transcription factor, by 1.46- and 2.71-fold, respectively, compared to the control treatment. Furthermore, combination treatment with TGF- $\beta 3$ and BMP-6 increased the expression of SOX9 by 3.97-fold compared with the control treatment. Further, the combination of both growth factors upregulated SOX9 expression compared to TGF- $\beta 3$ alone by 2.71 -fold and BMP- 6 alone by 1.46-fold. Aggrecan expression was also increased in the presence of the growth factors compared to the control treatment as follows: 4.69 -fold with TGF- $\beta 3,7.50$-fold with BMP-6 and 18.60 -fold with both. The expression of collagen type II was increased considerably more than the other markers in the presence of the growth factors. Specifically, TGF- $\beta 3$ increased collagen type II expression by 5.29 -fold, BMP-6 by 4.63 -fold and both by 23.15 -fold compared with the control treatment. Lastly, with respect to increases 
a
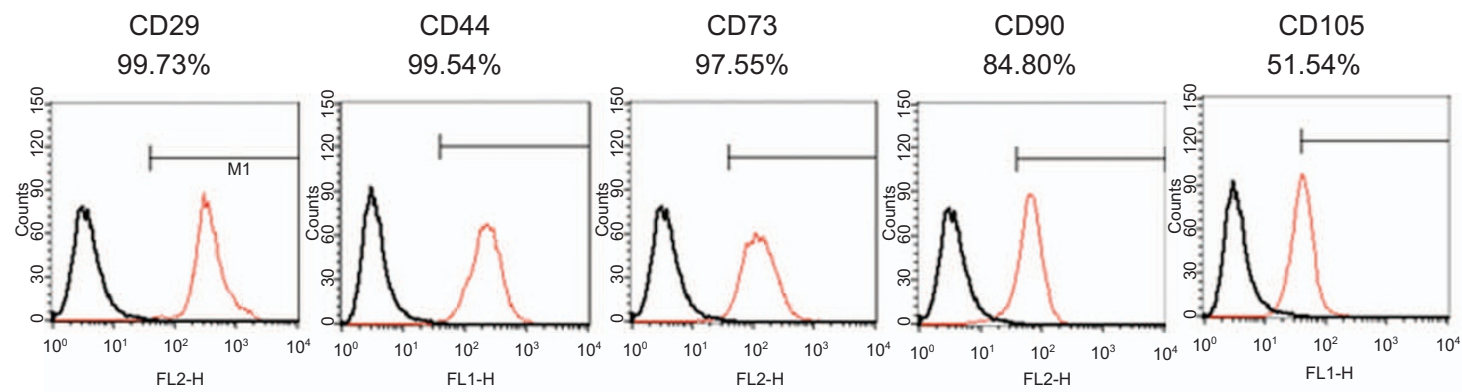

CD14

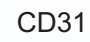

$0.17 \%$

CD34

$0.3 \%$
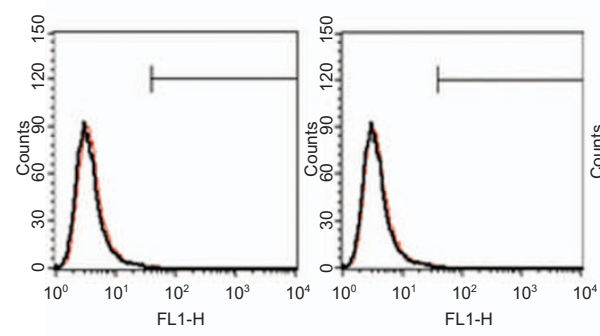

$0.35 \%$

CD45

$0.16 \%$

CD117

HLA-DR
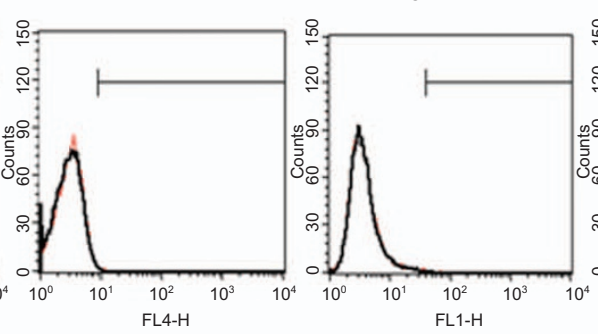

$0.17 \%$

$0.65 \%$
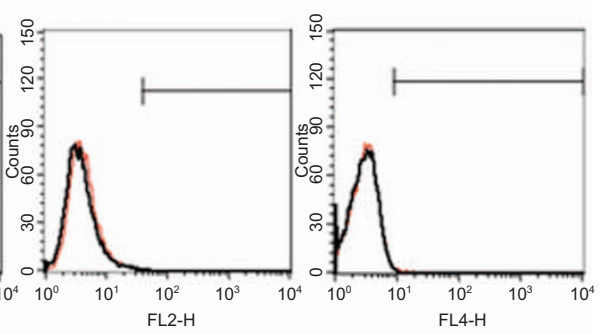

b

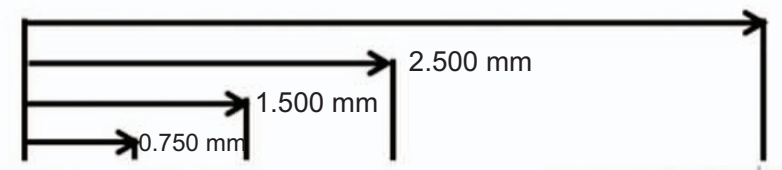

$5.000 \mathrm{~mm}$

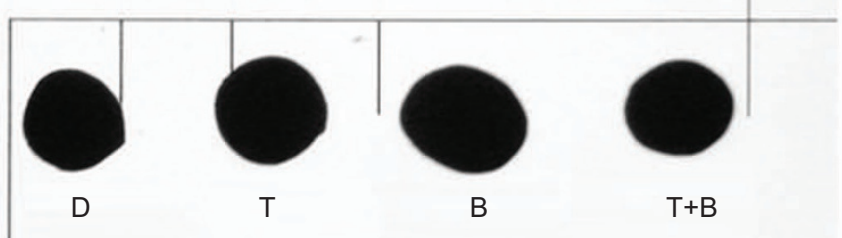

Figure 1 FACS analysis and macroscopic sizing. (a) Immunophenotype characterization of PDLSCs at passage 6. Cells were homogeneously positive for mesenchymal stem cell markers (99.73\% CD29, 99.54\% CD44, 97.55\% CD73, 84.80\% CD90, 51.54\% CD105) and negative for markers of hematopoietic stem cells or endothelial cells $(0.3 \%$ CD14, 0.17\% CD31, 0.35\% CD34, 0.16\% CD45, 0.17\% CD117, 0.65\% HLA-DR). (b) Picture of the chondro-balls cultured in four different kinds of chondrogenic media for 14 days. They were of similar size despite the different media compositions. D: control; T: $10 \mu \mathrm{g} \cdot \mathrm{L}^{-1} \mathrm{TGF}-\beta 3$, B: $100 \mu \mathrm{g} \cdot \mathrm{L}^{-1} \mathrm{BMP}-6$; $\mathrm{T}+\mathrm{B}: 10 \mu \mathrm{g} \cdot \mathrm{L}^{-1} \mathrm{TGF}-\beta 3$ plus $100 \mu \mathrm{g} \cdot \mathrm{L}^{-1} \mathrm{BMP}-6$. FACS, fluorescence-activated cell sorting; PDLSC, periodontal ligaments stem cell; TGF, transforming growth factor; BMP, bone morphogenetic protein.

a

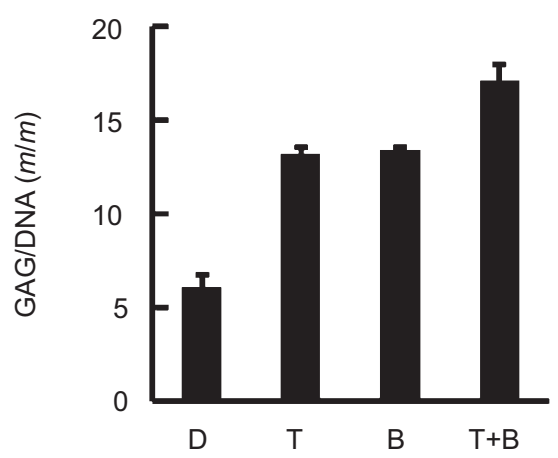

b

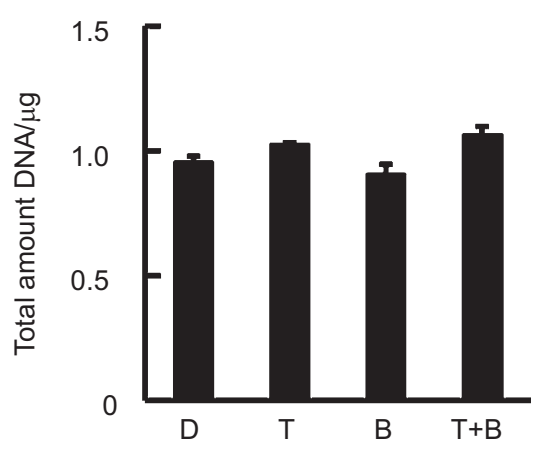

Figure 2 Differentiation ability of periodontal ligament derived cells into chondrocyte. (a) Relative amount of glycosaminoglycan/DNA content in each chondro-ball grown in the four different media types. GAG synthesis was increased by $217 \%$ in TGF- $\beta 3$ containing media and by $220 \%$ in BMP- 6 containing media. The presence of both TGF- $\beta 3$ and BMP-6 increased GAG synthesis by $281 \%$. (b) Total amount of DNA in each chondro-ball, indicating that the viability and proliferation of cells in the four conditions were similar, which implies that the results are reliable. D: control; T: $10 \mu \mathrm{g} \cdot \mathrm{L}^{-1} \mathrm{TGF}-\beta 3$, B: $100 \mu \mathrm{g} \cdot \mathrm{L}^{-1} \mathrm{BMP}-6$; T+B: $10 \mu \mathrm{g} \cdot \mathrm{L}^{-1} \mathrm{TGF}-\beta 3 \mathrm{plus}$ $100 \mu \mathrm{g} \cdot \mathrm{L}^{-1}$ BMP-6. GAG, glycosaminoglycan; TGF, transforming growth factor; BMP, bone morphogenetic protein. 
a

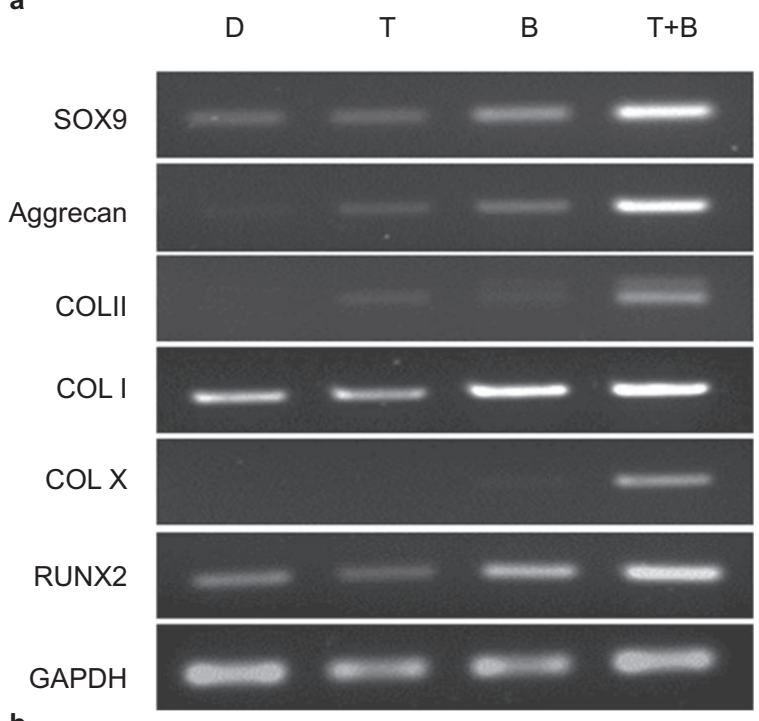

b

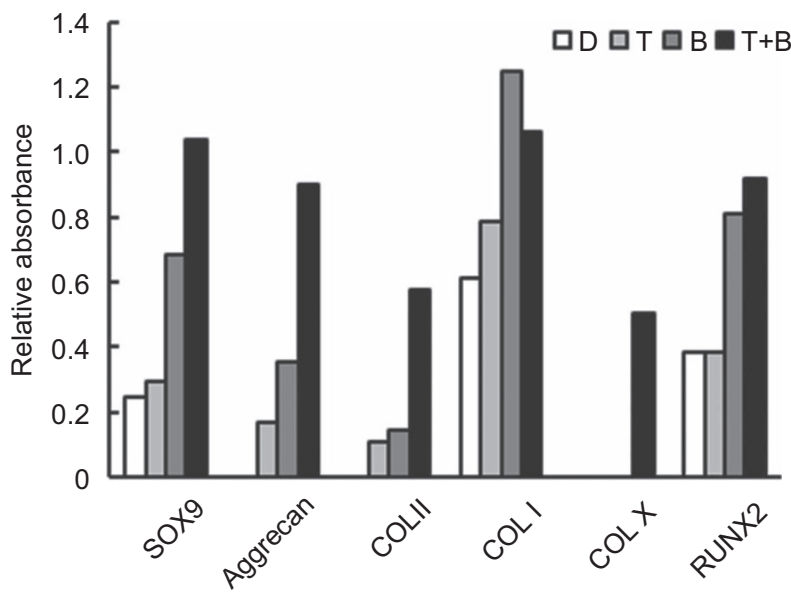

Figure 3 RT-PCR analysis during chondrogenesis of periodontal ligament derived cells. (a) RT-PCR assay for chondrogenesis-associated genes in PDLSCs. (b) The relative absorbance of each gene in the RT-PCR assay shows the relative gene expressions of each chondro-related RNA in the chondro-balls cultured in the four different chondrogenic media. The addition of TGF- $\beta 3$ or BMP- 6 considerably increased the expression of chondrocyte-related markers, SOX9, aggrecan (AGG), and collagen type II (COL2). Likewise, the combination of both growth factors was synergistic with respect to increased expression of these genes. The expression of Collagen type X (COLX) and RUNX2 were also induced by the growth factors. D: control; T: $10 \mu \mathrm{g} \cdot \mathrm{L}^{-1} \mathrm{TGF}-\beta 3$, B: $100 \mu \mathrm{g} \cdot \mathrm{L}^{-1} \mathrm{BMP}-6$; T+B: $10 \mu \mathrm{g} \cdot \mathrm{L}^{-1}$ TGF- $\beta 3$ plus $100 \mu \mathrm{g} \cdot \mathrm{L}^{-1}$ BMP-6. RT-PCR, reverse transcription-polymerase chain reaction; PDLSC, periodontal ligaments stem cell; TGF, transforming growth factor; BMP, bone morphogenetic protein.

in the expression of chondrocyte hypertrophy markers, the expression of collagen type $\mathrm{X}$ and Runx2, both osteogenic genes, were increased by medium containing both TGF- $\beta 3$ and BMP- 6 compared with the control treatment (Figure $3 \mathrm{a}$ and $3 \mathrm{~b}$ ).

\section{Histological and immunohistochemical analysis}

Hematoxylin and eosin staining showed that the cells cultured with BMP-6 were more spindle-shaped compared to others, and that cells grown in a cocktail of TGF- $\beta 3$ and BMP-6 had larger nuclei and appeared to be arranged in two layers, namely, an inner layer and an outer layer. In the inner layer, the cells and nuclei appeared round;
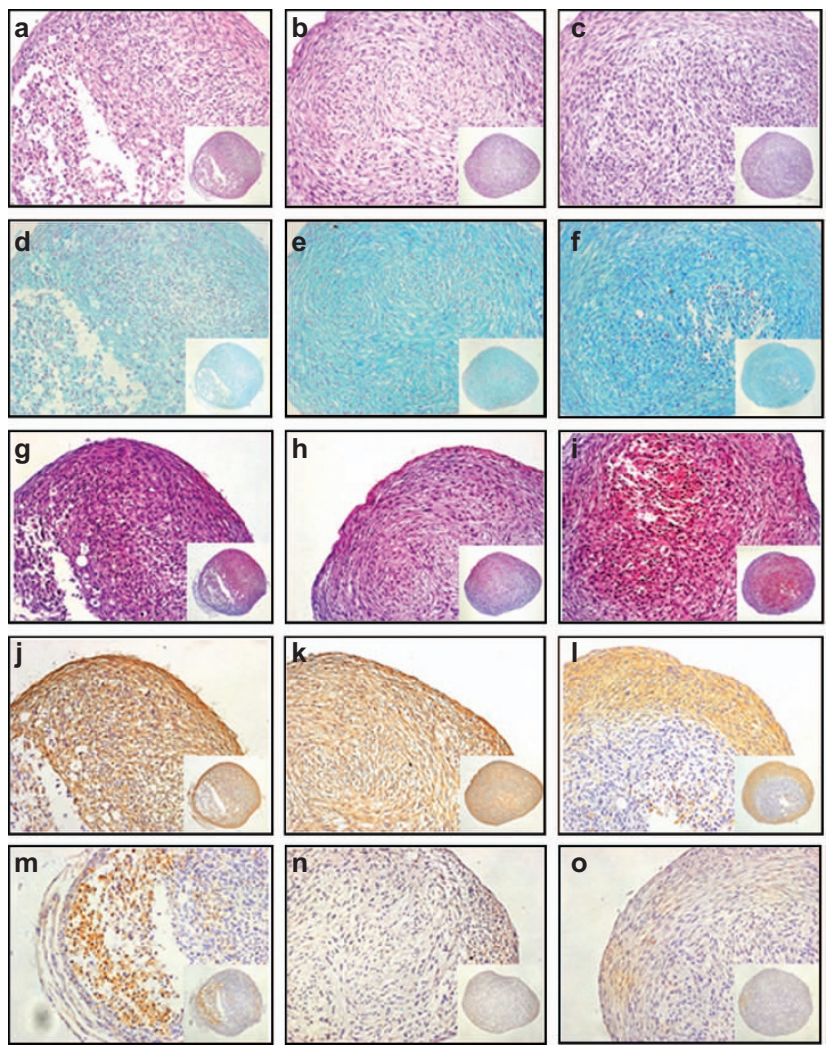

Figure 4 Histological and immunohistochemical analysis. PDLSCs cultured in the four different types of media for 14 days. (a-c) Hematoxylin and eosin staining of the chondro-balls seeded in $10 \mu \mathrm{g} \cdot \mathrm{L}^{-1} \mathrm{TGF}-\beta 3,100 \mu \mathrm{g} \cdot \mathrm{L}^{-1} \mathrm{BMP}-6$, and both $10 \mu \mathrm{g} \cdot \mathrm{L}^{-1}$ TGF- $\beta 3$ and $100 \mu \mathrm{g} \cdot \mathrm{L}^{-1}$ BMP-6, respectively. (d-f) Alcian blue staining of the chondro-balls seeded in $10 \mu \mathrm{g} \cdot \mathrm{L}^{-1} \mathrm{TGF}-\beta 3,100 \mu \mathrm{g} \cdot \mathrm{L}^{-1} \mathrm{BMP}-6$, and both $10 \mu \mathrm{g} \cdot \mathrm{L}^{-1} \mathrm{TGF}-\beta 3$ and $100 \mu \mathrm{g} \cdot \mathrm{L}^{-1}$ BMP-6, respectively. (g-i) Safranin 0 staining of the chondro-balls seeded in $10 \mu \mathrm{g} \cdot \mathrm{L}^{-1} \mathrm{TGF}-\beta 3,100 \mu \mathrm{g} \cdot \mathrm{L}^{-1} \mathrm{BMP}-6$, and both $10 \mu \mathrm{g} \cdot \mathrm{L}^{-1} \mathrm{TGF}-\beta 3$ and $100 \mu \mathrm{g} \cdot \mathrm{L}^{-1}$ BMP-6, respectively. (j-I) Type I collagen immunohistochemical staining of the chondro-balls seeded in $10 \mu \mathrm{g} \cdot \mathrm{L}^{-1}$ TGF- $\beta 3,100 \mu \mathrm{g} \cdot \mathrm{L}^{-1} \mathrm{BMP}-6$, and both $10 \mu \mathrm{g} \cdot \mathrm{L}^{-1} \mathrm{TGF}-\beta 3$ and $100 \mu \mathrm{g} \cdot \mathrm{L}^{-1} \mathrm{BMP}-6$, respectively. ( $\mathbf{m}-\mathbf{0})$ Type $\|$ collagen staining of the chondro-balls seeded in $10 \mu \mathrm{g} \cdot \mathrm{L}^{-1} \mathrm{TGF}-\beta 3,100 \mu \mathrm{g} \cdot \mathrm{L}^{-1} \mathrm{BMP}-6$, and both $10 \mu \mathrm{g} \cdot \mathrm{L}^{-1} \mathrm{TGF}-\beta 3$ and $100 \mu \mathrm{g} \cdot \mathrm{L}^{-1}$ BMP-6, respectively. PDLSC, periodontal ligaments stem cell; TGF, transforming growth factor; BMP, bone morphogenetic protein.

however, in the outer layer, the cells had a spindle shape. Alcian blue staining also showed a similar arrangement of the cells cultured in the cocktail. The nuclei of the cells were more prominent and round with safranin-O staining, while the layering pattern was clearly observed in the immunohistochemical staining for type I collagen. In the cells grown with both growth factors, the staining was much more intense in the outer layer of the cell clusters compared to the inner layer. Type I collagens were evenly distributed in the extracellular matrix in cells cultured in the TGF- $\beta 3$ or BMP- 6 medium. With respect to immunohistochemical staining for collagen type II, a pale brownish color was evenly distributed (Figure 4).

\section{DISCUSSION}

In this study, we demonstrated that human periodontal ligamentderived mesenchymal stem cells underwent chondrogenic induction upon treatment with growth factors, demonstrating sulfated glycosaminoglycan synthesis, expression of chondrogenesis-related genes, and increased chondrogenic protein abundance by immunohistochemistry. The growth factors TGF- $\beta 3$ and BMP- 6 not only induced 
chondrogenesis on their own, but also showed a synergistic effect. The ability of TGF- $\beta 3$ to enhance chondrogenic differentiation has been widely demonstrated and applied in various studies. ${ }^{16}$ BMP-6 induces chondrogenesis more efficiently than TGF- $\beta 3$ in adult stem cells derived from adipose tissue. ${ }^{17}$ TGF- $\beta 3$ and BMP- 6 may promote very early events in chondrogenesis and directly or indirectly maintain their regulation during the differentiation and maturation of chondrocytes. ${ }^{18}$ Similar to other stem cells, PDLSCs underwent chondrogenesis more efficiently in the presence of both TGF- $\beta 3$ and BMP- 6 . Even though there was no significant difference between the two growth factors in terms of induction, the combination of the growth factors stimulated increased chondrogenesis.

As shown in Figure 1a, the homogeneously high expression of CD29 ( $\beta 1$-integrin) and CD44 (hyaluronic acid receptor) indicated that the PDLSCs used in this study were mainly mesenchymal stem cells. ${ }^{14}$ CD90 (Thy-1) is a marker of various kinds of stem cells and specifically, it is a major marker of hematopoietic stem cells in combination with CD34. The CD90 positivity with the low level of CD34 expression demonstrated that there were few hematopoietic stem cells present in the isolated PDL cells. ${ }^{15}$ Further, the relatively low level of CD105 (endoglin), which is a specific marker for mesenchymal stem cells, implied the existence of an osteogenic differentiation process. ${ }^{14}$ Lastly, the low levels of CD14, a monocyte and macrophage marker, CD31, an endothelial cell marker, CD34, the hematopoietic early progenitor marker, CD45, the leukocyte common antigen, and CD117, a hematopoietic stem cell marker, demonstrated that the PDLSCs used in this study were not contaminated by hematopoietic stem cells or endothelial cells. In general, the cell surface marker expression of PDLSc showed similar expression as MSC. It means that the cells can be used as a strong stem cell source for cell therapy.

Chondrogenesis-related markers, SOX9, aggrecan, and collagen type II were all upregulated upon treatment with the growth factors. The first step in chondrogenesis is mesenchymal condensation mediated first by paracrine factors and subsequently by SOX9. ${ }^{19}$ Previous studies found that SOX9 is the clearest marker of chondrogenesis, as cells undergoing mesenchymal condensation begin to differentiate into chondrocytes. ${ }^{20-21}$ SOX9 is responsible for the expression of some of the key genes in chondrogenesis, namely SOX5, SOX6 and collagen II $\alpha 1$ (Col2 $\alpha 1) .{ }^{18}$ It was previously reported that the expression of SOX9 is regulated by members of the TGF- $\beta$, bone morphogenetic protein (BMP), FGF and Wnt families. ${ }^{22-23}$ Thus, the increased expression of SOX9 in our results implies the stimulation of chondrogenesis. However, the expression of both collagen type X, a hypertrophy-related factor, and Runx2, an osteogenesis-related factor, were also increased.

The mesenchymal stem cell properties of the cultured PDLSCs were indicated by the homogeneously positive expression of several stem cell specific markers on the surface, including CD29 and CD44. Furthermore, homogeneously negative expression of CD14, CD31, CD34, CD45 and CD117 indicated that the cells were not contaminated with hematopoietic stem cells or endothelial cells.

The growth factors enhanced the synthesis of GAG while maintaining a constant level of cell proliferation and viability. Proteoglycans are the second-most abundant proteins in cartilage matrix, and chondroitin sulfate is the predominant glycosaminoglycan in cartilage. ${ }^{24}$ The combination of growth factors induced more GAG production, which confirmed their synergistic effect. This was also supported by the increased expression of chondrogenesis-related genes. In response to the growth factors, chondrogenesis-related genes, SOX9, aggrecan and collagen type 10, were upregulated. The expression of aggrecan and collagen type II were considerably increased by the cocktail of the growth factors. Aggrecan, one of the substrates of chondroitin sulfate, is the most abundant proteoglycan in cartilage. ${ }^{25}$ Deposition of aggrecan has been considered a hallmark of chondrogenesis. ${ }^{26}$

Immunohistochemical staining indicated synthesis of type I and type II collagens in the extracellular matrix. Cells cultured in BMP-6 medium appeared to be more spindle-shaped than others, and those grown in both TGB- $\beta 3$ and BMP- 6 seemed arranged in two distinct layers, namely, an inner layer and an outer layer. Most of the results suggest that the growth factors TGF- $\beta 3$ and BMP- 6 induced chondrogenesis in PDLSCs; however, expression of several unexpected markers such as collagen type $\mathrm{X}$ and Runx 2 were also stimulated by the growth factors. This limitation should be evaluated in further studies. PDLSCs showed a similar pattern of chondrogenic differentiation compared with other stem cells, expressing chondrogenesis-related genes and synthesizing extracellular matrix proteins successfully in the presence of growth factors.

Since PDLSCs are neural crest origin, known as a type of MSC, have a high proliferative and multipotent capacity. Extracted supernumerary or the third molar teeth, which was wastes of dental procedures, might be a valuable stem cell sources. In technically, getting bone marrow is aggressive, and needing general anesthesia but teeth can be easily obtained during dental treatment. In this reason, MSC from teeth, like PDLSc, can be banked for long period and used as a source of stem cell therapy for many diseases. ${ }^{27-28}$

In summary, we investigated the stem cell properties of PDL cells by inducing chondrogenesis using growth factors, TGF- $\beta 3$ and BMP-6. This work demonstrated the potential of dental stem cells as a valuable cell source for chondrogenesis, which can be applied to the regeneration of cartilage in the tissue engineering field. These results also confirm that PDLSCs can be used in tissue-engineering approaches for the treatment of osteoarthritis, temporomandibular joint disorder, and cartilage reconstruction.

\section{ACKNOWLEDGEMENTS}

This research was supported by the Bio \& Medical Technology Development Program of the National Research Foundation (NRF) funded by the Korean government (MEST) (No. 860-20110087).

1 Blau HM, Brazelton TR, Weimann JM. The evolving concept of a stem cell: entity or function? Cell 2001; 105(7): 829-841.

2 Bosnakovski D, Mizuno M, Kim G et al. Chondrogenic differentiation of bovine bone marrow mesenchymal stem cells (MSCs) in different hydrogels: Influence of collagen type II extracellular matrix on MSC chondrogenesis. Biotechnol Bioeng 2006; 93(6): 1152-1163.

3 Zhang W, Yelick PC. Vital pulp therapy-current progress of dental pulp regeneration and revascularization. Int J Dent 2010; 2010: 856087. doi: 10.1155/2010/856087. Epub 2010 Apr. 28.

4 Ohta S, Yamada S, Matuzaka K et al. The behavior of stem cells and progenitor cells in the periodontal ligament during wound healing as observed using immunohistochemical methods. J Periodontal Res 2008; 43(6): 595-603.

5 Seo BM, Miura M, Gronthos S et al. Investigation of multipotent postnatal stem cells from human periodontal ligament. Lancet 2004; 364(9429): 149-155.

6 Nagatomo K, Komaki M, Sekiya I et al. Stem cell properties of human periodontal ligament cells. J Periodontal Res 2006; 41(4): 303-310.

7 Gay IC, Chen S, MacDougall M. Isolation and characterization of multipotent human periodontal ligament stem cells. Orthod Craniofac Res 2007; 10(3): 149-160.

$8 \mathrm{Ma} Z$, Li S, Song Y et al. The biological effect of dentin noncollagenous proteins (DNCPs) on the human periodontal ligament stem cells (HPDLSCs) in vitro and in vivo. Tissue Eng Part A 2008; 14(12): 2059-2068.

9 Inoue T, Deporter DA, Melcher AH. Induction of chondrogenesis in muscle, skin, bone marrow, and periodontal ligament by demineralized dentin and bone matrix in vivo and in vitro. J Dent Res 1986; 65(1): 12-22.

10 Hoffman LM, Weston AD, Underhill TM. Molecular mechanisms regulating chondroblast differentiation. J Bone Joint Surg Am 2003; 85-A (Suppl 2): 124-132. 
11 Lee JY, Nam H, Park YJ et al. The effects of platelet-rich plasma derived from human umbilical cord blood on the osteogenic differentiation of human dental stem cells. In Vitro Cell Dev Biol Anim 2011; 47(2): 157-164.

12 Cho TJ, Kim JH, Kwon SK et al. A potent small-molecule inducer of chondrogenic differentiation of human bone marrow-derived mesenchymal stem cells. Chem Sci 2012; 3: 3071-3075.

13 Sakaguchi Y, Sekiya I, Yagishita $\mathrm{K}$ et al. Suspended cells from trabecular bone by collagenase digestion become virtually identical to mesenchymal stem cells obtained from marrow aspirates. Blood 2004; 104(9): 2728-2735.

14 Bruder SP, Horowitz MC, Mosca JD et al. Monoclonal antibodies reactive with human osteogenic cell surface antigens. Bone 1997; 21(3): 225-235.

15 Craig W, Kay R, Cutler RL et al. Expression of Thy-1 on human hematopoietic progenitor cells. J Exp Med 1993; 177(5): 1331-1342.

16 Tang QO, Shakib K, Heliotis M et al. TGF-beta3: a potential biological therapy for enhancing chondrogenesis. Expert Opin Biol Ther 2009; 9(6): 689-701.

17 Estes BT, Wu AW, Guilak F. Potent induction of chondrocytic differentiation of human adipose-derived adult stem cells by bone morphogenetic protein 6 . Arthritis Rheum 2006; 54(4): 1222-1232.

18 Quintana L, zur Nieden NI, Semino CE. Morphogenetic and regulatory mechanisms during developmental chondrogenesis: new paradigms for cartilage tissue engineering. Tissue Eng Part B Rev 2009; 15(1): 29-41.

19 Akiyama $\mathrm{H}$, Chaboissier MC, Martin JF et al. The transcription factor Sox9 has essential roles in successive steps of the chondrocyte differentiation pathway and is required for expression of Sox5 and Sox6. Genes Dev 2002; 16(21): 2813-2828.

20 Healy C, Uwanogho D, Sharpe PT. Expression of the chicken Sox9 gene marks the onset of cartilage differentiation. Ann N Y Acad Sci 1996; 785: 261-262.
21 Wright E, Hargrave MR, Christiansen J et al. The Sry-related gene Sox9 is expressed during chondrogenesis in mouse embryos. Nat Genet 1995; 9(1): 15-20.

22 DeLise AM, Fischer L, Tuan RS. Cellular interactions and signaling in cartilage development. Osteoarthritis cartilage 2000; 8(5): 309-334.

23 Kawakami Y, Rodriguez-Leon J, Izpisua Belmonte JC. The role of TGFbetas and Sox9 during limb chondrogenesis. Curr Opin Cell biol 2006; 18(6): 723-729.

24 Zhang G, Eames BF, Cohn MJ. Chapter 2. Evolution of vertebrate cartilage development. Curr Top Dev Biol 2009; 86: 15-42. doi: 10.1016/s0070-2153(09)01002-3.

25 Doege KJ, Sasaki M, Kimura T et al. Complete coding sequence and deduced primary structure of the human cartilage large aggregating proteoglycan, aggrecan. Humanspecific repeats, and additional alternatively spliced forms. J Biol Chem 1991; 266(2): 894-902.

26 Schwartz NB, Pirok EW 3rd, Mensch JR Jr et al. Domain organization, genomic structure, evolution, and regulation of expression of the aggrecan gene family. Prog Nucleic acid Res Mol Biol 1999; 62: 177-225.

27 Rosa V, Della Bona A, Cavalcanti BN et al. Tissue engineering: from research to dental clinics. Dent Mater 2012; 28(4): 341-348.

28 Yen AH, Yelick PC. Dental tissue regeneration-a mini-review. Gerontology 2011; 57(1): 85-94.

(c) This work is licensed under a Creative Commons

Attribution-NonCommercial-NoDerivative Works 3.0

Unported License. To view a copy of this license, visit http:// creativecommons.org/licenses/by-nc-nd/3.0 